\title{
МОДИФИКАЦИЯ ВОДОРАЗБАВЛЯЕМОЙ ГРУНТОВКИ ВКФ-093 ДЛЯ ЭЛЕКТРООСАЖЕНИЯ
}

\author{
Г.Н. Беспалова, А. К. Морохина, Е. К. Шабунин, Т.А. Агеева, О. И. Койфман \\ ГАЛИНА НИКОЛАЕВНА БЕСПАЛОВА - кандидат технических наук, дочент кафедры Химии и техноло- \\ гии высокомолекулярных соединений ФГБОУ ВО «Ивановского государственного химико-технологическо- \\ го университета». Область научных интересов: модификаџия водоразбавляемых материалов для элек- \\ троосаждения. Тел.: 8-962-168-85-17.E-mail: kraska@isuct.ru. \\ АЛЕКСАНДРА КОНСТАНТИНОВНА МОРОХИНА- аспирант кафедры Химии и технологии высокомоле- \\ кулярных соединений ФГБОУ ВО «Ивановского государственного химико-технологического университе- \\ та». Область научных интересов: модификация водоразбавляемых материалов для электроосаждения. \\ E-mail: sashamorohina@mail.ru.
}

ЕВГЕНИЙ КОНСТАНТИНОВИЧ ШАБУНИН-магистрант кафедры Химии и технологии высокомолекулярных соединений ФГБОУ ВО «Ивановского государственного химико-технологического университета». Область научных интересов: модификация водоразбавляемых материалов для электроосаждения. E-таіl: shabynin2@mail.ru.

ТАТЬЯНА АРСЕНЬЕВНА АГЕЕВА- кандидат химических наук, доиент кафедры Химии и технологии высокомолекулярных соединений ФГБОУ ВО «Ивановского государственного химико-технологического университета». Область научных интересов: синтез и исследование порфиринсодержащих полимеров и новых функииональных материалов на их основе. E-mail: tageeva@isuct.ru.

ОСКАР ИОСИФОВИЧ КОЙФМАН - член-корреспондент РАН, доктор химических наук, заведуюший кафедрой Химии и технологии высокомолекулярных соединений ФГБОУ ВО «Ивановского государственного химико-технологического университета», заведующий лабораторией Института химии растворов им. Г.А. Крестова PAH.E-mail:koifman@isuct.ru.

153000, г. Иваново, пр. Шереметевский, д. 7. ФГБОУ ВО «Ивановский государственньий химико-технологический университет».

В работе представлены предложенная методика введения катализатора - резината кобальта в состав водоразбавляемых композиций для электроосаждения на основе грунтовки ВКФ-093 и результаты исследований коллоидно-химических свойств получаемой композиции и режимов нанесения на окрашиваемье поверхности.

Ключевые слова: лакокрасочные покрытия, анодное электроосаждение, модифицирующие добавки, водоразбавляемые композиции, каталитическое отверждение. 


\title{
MODIFICATION OF WATERBORNE PRIMER VKF-093 FOR ELECTRODEPOSITION
}

\author{
G. N. Bespalova, A. K. Morokhina, E. K. Shabunin, T. A. Ageeva, O. I. Koifman \\ 7, Sheremetevsky av., Russian Federation, Ivanovo, 153000. Ivanovo State University of Chemistry and Technology
}

The paper presents the proposed method for introducing a catalyst-cobalt resinate into the composition of water-borne compositions for electrodeposition based on VKF-093 primer and the results of studies of the colloidchemical properties of the resulting composition and application modes on the painted surfaces.

Key words: paint and varnish coatings, anodic electrodeposition, modifying additives, waterborne compositions, catalytic curing.

Одной из основных тенденций развития современной лакокрасочной промышленности является стремление уменьшить или полностью исключить применение токсичных, пожароопасных и достаточно дорогих органических растворителей. Это привело к созданию водоразбавляемых материалов, порошковых красок, лакокрасочных систем, полимеризующихся непосредственно на защищаемой поверхности.

Основное назначение полимерных покрытий состоит в защите металлических изделий от коррозии и придании им красивого внешнего вида.

Химические и физико-химические реакции, возникающие в момент взаимодействия окружающей среды с металлами и сплавами, в большинстве случаев приводят к их самопроизвольному разрушению. Процесс саморазрушения имеет собственный термин - «коррозия». То, насколько быстро будет происходить процесс коррозии, полностью зависит от условий, в которые помещено изделие. Результатом коррозии является существенное ухудшение свойств металла, вследствие чего изделия из него быстро выходят из строя. Основной способ защиты металла от коррозии - создание защитных полимерных покрытий. Наиболее полно реализовать защитный, антикоррозионный потенциал полимерных, лакокрасочных покрытий можно при использовании современного способа окрашивания - электроосаждения.

Электроосаждение - это метод получения грунтовочных и однослойных лакокрасочных покрытий на изделиях из черных и цветных металлов из водных растворов под действием электрического тока. Метод электроосаждения обеспечивает высокие антикоррозионные и физико-механические свойства однослойных покрытий толщиной 10...30 мкм, равномерную окраску скрытых сечений в изделиях сложной конфигурации при малом расходе лакокрасочных материалов.
В настоящее время метод электроосаждения широко используется в автомобильной промышленности для грунтования кузовов автомобилей, он применяется также для окраски электробытовых машин и приборов, в сельхозмашиностроении, электротехнической, радиотехнической промышленностях и других отраслях.

С самого начала использования водоразбавляемых лакокрасочных материалов для электроосаждения и до настоящего времени ощущается острый недостаток в таких материалах. Улучшения качества и придания покрытиям на их основе нужных свойств можно добиться либо созданием новых материалов, либо путем модификации уже существующих.

Одним из серьезных недостатков водоразбавляемых грунтовок ВКЧ-0207 и ВКФ -093 для анодного электроосаждения является высокая температура формирования покрытий $\left(180 \ldots 200{ }^{\circ} \mathrm{C}\right)$. Использование таких температур обусловливает повышенную энергоёмкость технологии получения полимерных пленок. В связи с этим целью исследования является снижение температуры структурирования электроосажденных покрытий или продолжительности их формирования.

Одним из эффективных и малозатратных путей решения означенных проблем является введение в состав олигомерных водоразбавляемых композиций целевых модифицирующих добавок. При введении добавок не должны изменяться свойства водных олигомерных композиций, такие как электропроводность, величина $\mathrm{pH}$, агрегативная и седиментационная устойчивость системы. Также не должна ухудшаться их рассеивающая способность. В связи с этим технология введения водонерастворимых добавок-модификаторов должна предусматривать их внедрение в гидрофобное ядро мицеллы плёнкообразователя, а не в водную фазу композиции. Такое модифици- 
рование обеспечивает постоянство соотношения «плёнкообразователь:модификатор» как в раствоpe, так и в получаемом покрытии в течение всего срока эксплуатации композиции [1]. В качестве таких модификаторов нами были выбраны металлопорфирины природного происхождения.

Благодаря набору физических и химических свойств порфирины и их аналоги привлекают интерес исследователей в области химии, биологии, медицины, оптики и др. Наличие в составе молекул двойных связей, хромофорных и ауксохромных групп придаёт им способность окрашивать полимерные покрытия. Одновременно присутствие поливалентных металлов, таких как кобальт, медь и другие, даёт основание предполагать, что металлопорфирины могут проявлять каталитическую активность в процессе окислительной полимеризации ненасыщенных плёнкообразователей при отверждении покрытий [2].

Действительно, как показали результаты экспериментов с металлопорфиринами, они обладают высокой эффективностью действия, катализируя процесс отверждения электроосажденных покрытий. Наиболее результативные показатели были получены при использовании кобальтового (II) комплекса феофитина «а» и медного (II) комплекса метилфеофорбида «а», вводимых в состав водных композиций в очень малых количествах $10^{-4}$ г/дл [3].

Однако существенным недостатком металлопорфиринов является высокая стоимость и достаточная трудоёмкость процесса их синтеза.

В связи с этим актуальной задачей являлся поиск более дешевых по стоимости и менее трудоёмких по производству добавок - катализаторов. Для этого были исследованы различные типы соединений кобальта, меди и др. Из всех исследованных веществ были выделены сиккативы (соли металлов переменной валентности, такие как резинаты, линолеаты, нафтенаты металлов). Эти соединения используются на практике для ускорения процесса отверждения покрытий, полученных из органорастворимых материалов, нанесение которых на металлические поверхности осуществляется традиционными способами (пневмораспыление, окунание, кисть и др.), при этом количество вводимого в лакокрасочный материал сиккатива достигает 5-7 \%, что совершенно недопустимо для введения в водоразбавляемые материалы, наносимые электроосаждением. Они теряют свою агрегативную и седиментационную устойчивость, из них невозможно получать качественные защитные покрытия.

\section{Экспериментальная часть}

Задача исследования заключалась в оптимизации метода введения сиккативов, в частности, резината кобальта в состав водоразбавляемой грунтовки ВКФ-093, изучении коллоидно-химических свойств получаемой композиции и оценке свойств электроосажденных покрытий.

Для разработки технологии приготовления водных модифицированных композиций, обладающих хорошей работоспособностью и высокой стабильностью, были опробованы различные способы введения нерастворимых в воде модификаторов в состав рабочих растворов для электроосаждения. Оптимальным способом, обеспечивающим получение стабильных, не расслаивающихся композиций, оказался способ введения модификаторов в исходную грунтовку ВКФ-093 в виде раствора в органических растворителях, не смешивающихся с водой.

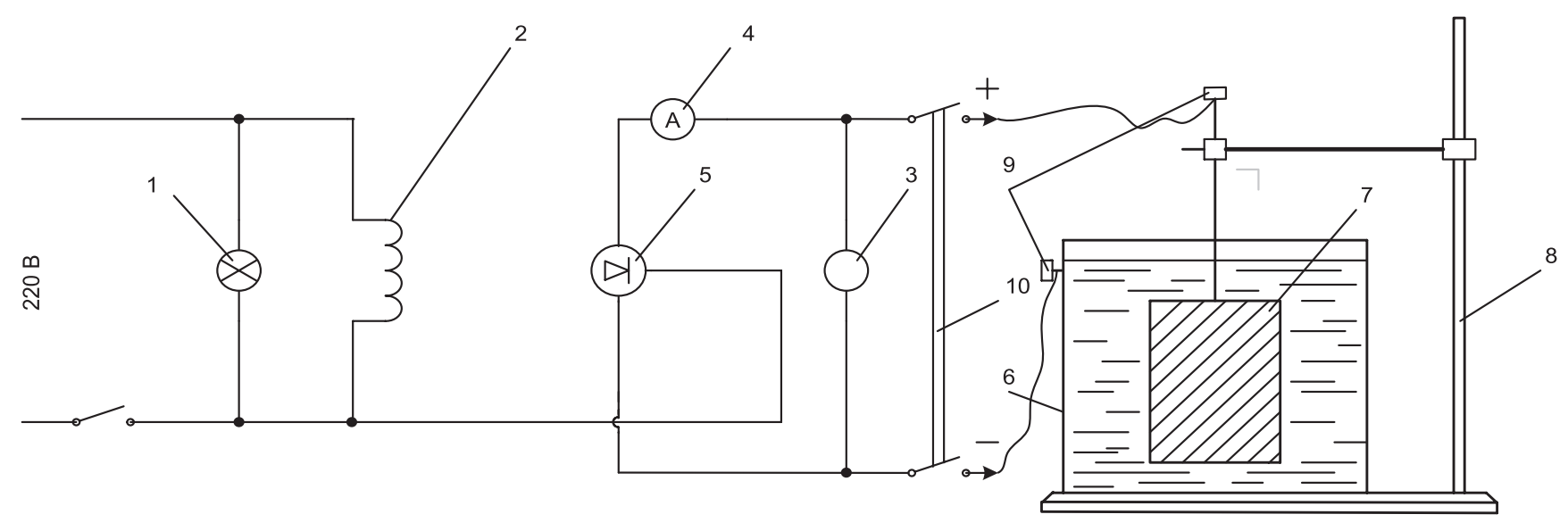

Рис. 1. Схема лабораторной установки электроосаждения:

1 - сигнальная лампочка; 2 - автотрансформатор; 3 -вольтметр; 4 -амперметр; 5 - выпрямитель; 6-ванна; 7 -образец; 8-штатив; 9-зажимы; 10 -переключатель 


\section{Приготовление композищий}

Приготовление $10 \%$-ной водной модельной композиции (композиции сравнения) из расчета на 100 г рабочего раствора. К 14 г грунтовки ВКФ093 для перевода ее в водоразбавляемое состояние добавляется нейтрализатор - 1,3 мл триэтиламина. Смесь тщательно перемешивается в течение 15 мин, затем к ней при постоянном перемешивании небольшими порциями добавляется дистиллированная вода до достижения общей массы 100 г. После добавления всей порции воды композиция перемешивается 10 мин. Визуально проверяется ее однородность.

Приготовление модифицированной композиции из расчета на 100 г рабочего раствора. К 14 г грунтовки ВКФ-093 добавляется $m$ г резината кобальта в виде раствора в толуоле. Масса перемешивается 15 мин, затем в смесь вводится нейтрализатор - 1,3 мл триэтиламина. После перемешивания в течение 10 мин вводится дистиллированная вода до 100 г с последующим перемешиванием и проверкой однородности полученной композиции.

\section{Методы исследования}

Для изучения свойств полученных композиций были использованы следующие методы исследования: 2211);

- pH-метрия (прибор HANNA instruments HI

- метод динамического рассеяния света (прибор PHOTOCOR Compact-Z).

Нанесение покрытий из водоразбавляемых композиций на металлические образцы проводилось на установке для анодного электроосаждения в потенциостатическом режиме (рис. 1).

Для исследования свойств электроосажденных покрытий были использованы стандартные методики, принятые в технологии лакокрасочных покрытий [4]:

- определение удельной массы покрытий гравиметрический метод (электронные весы ОКБ «BECTA»);

- определение прочности пленки при изгибе (ГОСТ 6806-73);

- определение прочности покрытия при ударе (ГОСТ 4765-73);

- определение адгезии покрытия методом решетчатых надрезов (ГОСТ 15140-78);

- определение твердости покрытия по карандашу «Конструктор» [5];

- определение водостойкости, солестойкости и кислотостойкости покрытий (метод погружения в воду, в $3 \%$-й раствор хлорида натрия и в $3 \%$-й раствор серной кислоты соответственно);

- определение степени отверждения покрытий по содержанию в них гель-золь-фракций осуществлялось в экстракторе Сокслета.

Метод определения степени отверждения покрытий основан на способности растворимой части пленки (золь-фракция) вымываться растворителем и заключается в количественном определении золь-фракции $(\mathrm{Z})$, не связанной в полимерную сетку (гель-фракция).

Содержание гель-фракции (G), (\%) вычисляется по формуле:

$$
\mathrm{G}=100-\mathrm{Z}
$$

\section{Результаты и их обсуждение}

Коллоидные системы, обладающие большой удельной поверхностью и большой свободной энергией являются принципиально неравновесными системами. Очевидно, они всегда будут стремиться к равновесному состоянию, отвечающему разделению системы на две фазы с минимальной межфазной поверхностью (хотя это равновесие практически никогда может и не наступить) [3].

Исследуемые нами композиции относятся к таким дисперсным системам, поэтому вопросы, связанные с изучением их стабильности, являются важными при создании материалов, предназначенных для электроосаждения. Одним из показателей, определяющих устойчивость коллоидных систем, a также их электрофоретическую подвижность, является величина ל-потенциала. Сравнительные

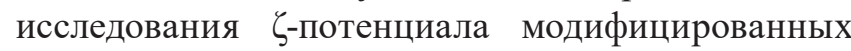
и немодифицированных водоразбавляемых композиций на основе грунтовки ВКФ-093 от ее концентрации $\zeta=f(c)$ в диапазоне $0,039 . .10,0$ мас. \%., представлены на рис. 2. Концентрация модификатора составляет $0,01 \ldots 0,015$ г/дл в пересчете на чистый кобальт.

Полученные зависимости изменения $\zeta$-потенциала от концентрации композиции имеют вид, типичный для коллоидных систем. Введение катализатора - модификатора в состав композиций не оказывает существенного влияния на свойства композиции и ее электрофоретическую подвижность, особенно в области рабочих концентраций композиции (6-10 мас. \%).

Зависимости изменения величины $\mathrm{pH}$ растворов при разбавлении $\mathrm{pH}=\mathrm{f}(\mathrm{c})$ представлены на рис. 3.

При разбавлении водой происходит перестройка мицеллы, вследствие чего её диффузный слой расширяется. Это способствует переходу всё 


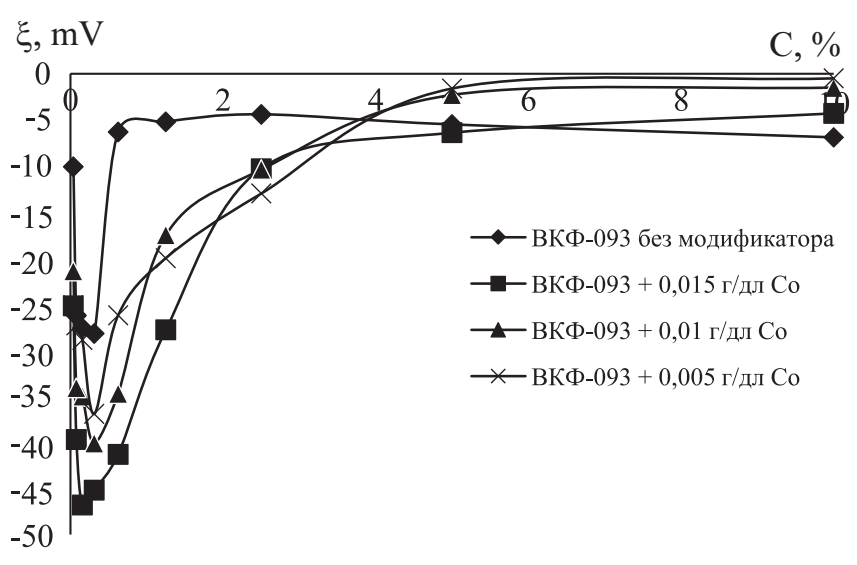

Рис. 2. Зависимость изменения Ђ-потенциала от концентрации растворов при различном содержании катализатора

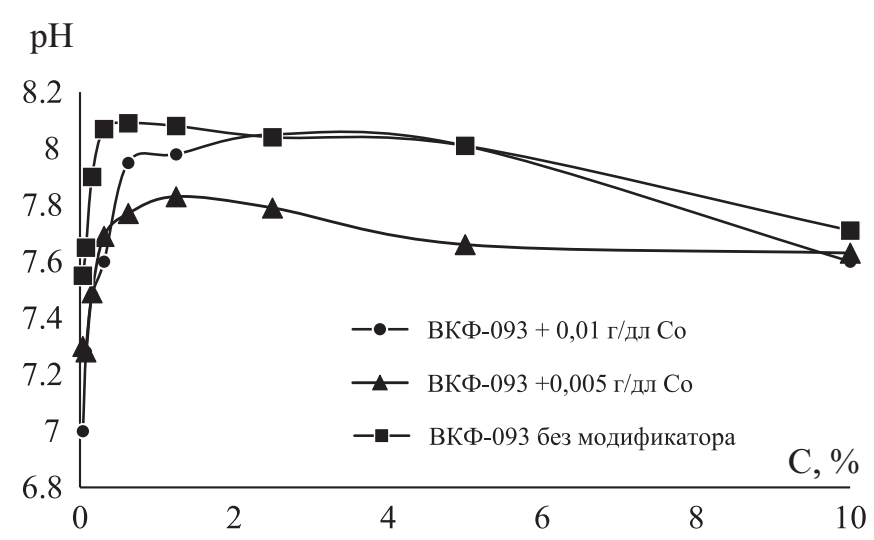

Рис. 3. Зависимость величины рН водных растворов плёнкообразователей от их концентрации и добавок катализатора

большего числа противоионов $\mathrm{R}_{3} \mathrm{~N}^{+} \mathrm{H}$ из адсорбционного слоя в диффузный. Концентрация их в дисперсионной среде увеличивается. Одновременно с этим увеличивается число свободных зарядов карбанионов $\mathrm{RCOO}^{-}$на поверхности мицеллы.

При взаимодействии с водой возможна частичная регенерация карбоксильных групп очень слабых олигомерных поликислот плёнкообразователя [1]:

$$
\mathrm{RCOO}^{-}+\mathrm{H}_{2} \mathrm{O}=\mathrm{RCOOH}+\mathrm{OH}^{-}
$$

что и обусловливает возрастание величины $\mathrm{pH}$ раствора при разбавлении композиции.

Однако, в отличие от поведения непигментированных водоразбавляемых композиций введение наполнителя - неорганического пигмента вносит определенные поправки. Взаимодействие полимера с поверхностью твердого наполнителя приводит к тому, что каждая частица пигмента покрывается тонкой пленкой полимера, в которой макромолекулы ориентированы таким образом, что их полярные группы обращены к полярным группам наполнителя. Взаимодействие полимера с поверхностью наполнителя существенно уменьшает молекулярную подвижность макромолекул в этом граничном слое, что приводит к изменению структуры и свойств граничного слоя и, как следствие, изменению релаксационных и механических свойств системы [6]. В результате протекания указанных процессов на изучаемых зависимостях отсутствует экстремальный характер кривых $\mathrm{pH}=\mathrm{f}(\mathrm{c})$ при низких значениях концентраций, как это наблюдалось в непигментированных композициях $[3,7]$.

Окрашивание стальных образцов осуществлялось на установке для анодного электроосаждения (рис. 1).

Оптимизация параметров электроосаждения по удельной массе $\left(\mathrm{m}_{\text {уд }}\right)$ и качеству покрытий проводилась по напряжению окрашивания $\mathrm{m}_{\mathrm{yд}}=\mathrm{f}(\mathrm{U})$ из $10 \%$-х водных растворов грунтовки ВКФ-093 с добавками катализатора и без них (рис. 4). Исследования показали, что достаточная величина удельной массы $\left(\mathrm{m}_{\text {уд }}\right)$ и хорошее качество покрытий наблюдаются в диапазоне напряжений $60 \ldots 90$ В Поэтому все дальнейшие исследования процессов отверждения покрытий, проверки их физико-механических и противокоррозионных свойств проводились на образцах, окрашенных при напряжении 60 В в течение 60 сек.

Исследование процессов отверждения проводилось при температурах $160{ }^{\circ} \mathrm{C}$ и $180{ }^{\circ} \mathrm{C}$ по содержанию гель-фракции в покрытиях. Стандартный режим отверждения грунтовки ВКФ-093: $180{ }^{\circ} \mathrm{C}$, 30 мин. Сравнительная характеристика процессов структурирования покрытий, полученных из водной грунтовки ВКФ-093 (базовая композиция) и отвержденных при различных температуpax, (рис. 5) свидетельствует о том, что при $160{ }^{\circ} \mathrm{C}$ получаются покрытия с низким содержанием G-фракции, что не позволяет использовать их при дальнейшей эксплуатации.

Введение модификатора существенно изменяет скорость формирования покрытий (рис. 6). Как видно из представленной сравнительной гистограммы, покрытия, полученные из композиций, содержащих модифицирующую добавку и отвержденные при $160{ }^{\circ} \mathrm{C}$, значительно превосходят по величине G-фракции покрытия из базовой композиции, отвержденные при $180{ }^{\circ} \mathrm{C}$ за тот же временной интервал.

На гистограмме (рис. 7) видно, что при использовании композиции, содержащей катализатор, покрытия можно отверждать при $180{ }^{\circ} \mathrm{C}$, но уже 


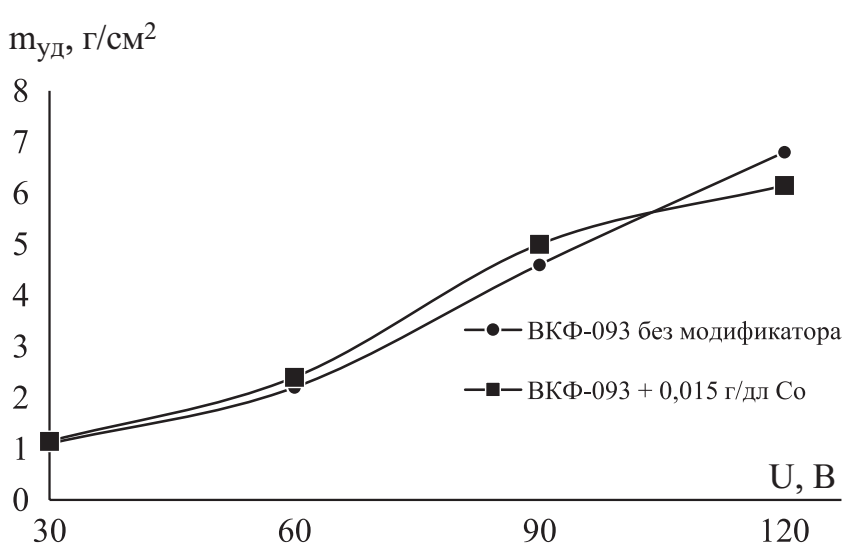

Рис. 4. Зависимость удельной массы покрытий от напряжения

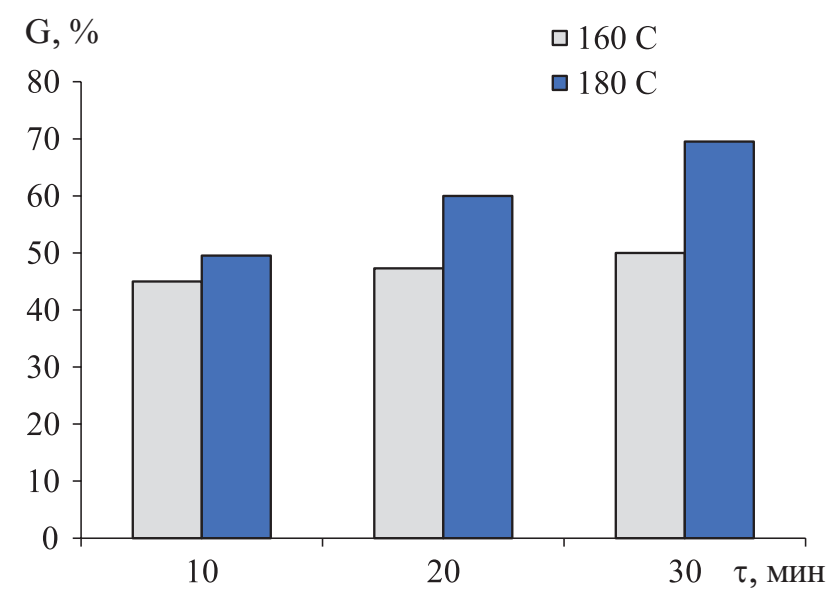

Рис. 5. Влияние температуры отверждения покрытий на основе грунтовки ВКФ-093 на содержание G-фракции

не 30 мин, как указано в стандарте на этот материал, а за значительно меньший период - 15..20 мин.

Исходя из полученных результатов, для практического использования могут быть рекомендованы два режима пленкообразования покрытий, получаемых из модифицированных композиций:

1. Температура $-180^{\circ} \mathrm{C}$, продолжительность15 мин.

2. Температура $-160^{\circ} \mathrm{C}$, продолжительность30 мин.

Оценка физико-механических и противокоррозионных свойств покрытий проводилась по стандартным методикам, принятым в технологии лакокрасочных покрытий.

Исследования показали, что физико-механические свойства покрытий соответствуют техническим показателям как при отверждении по стандартному режиму, так и при пониженной до $160{ }^{\circ} \mathrm{C}$ температуре. Введение в состав композиции ка-
$160{ }^{\circ} \mathrm{C}$

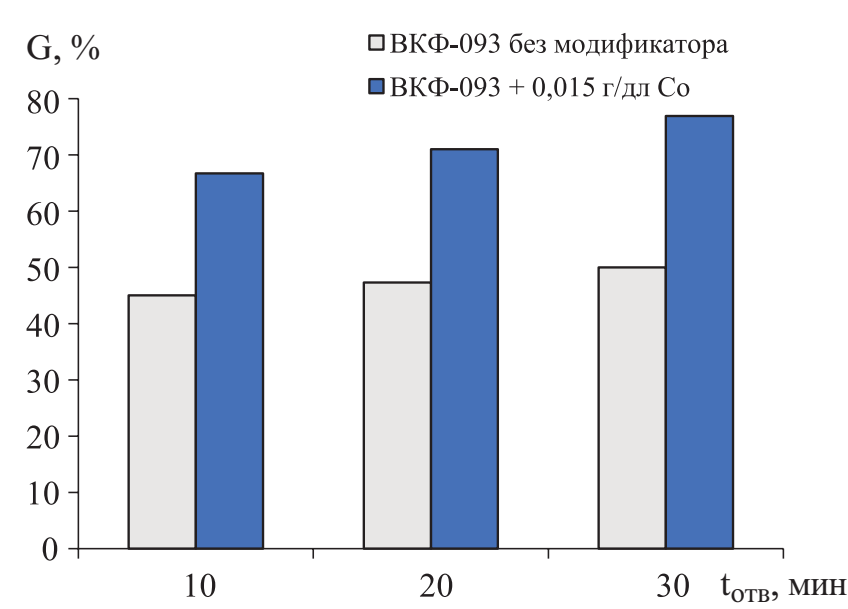

Рис. 6. Влияние времени отверждения покрытий на содержание G-фракции

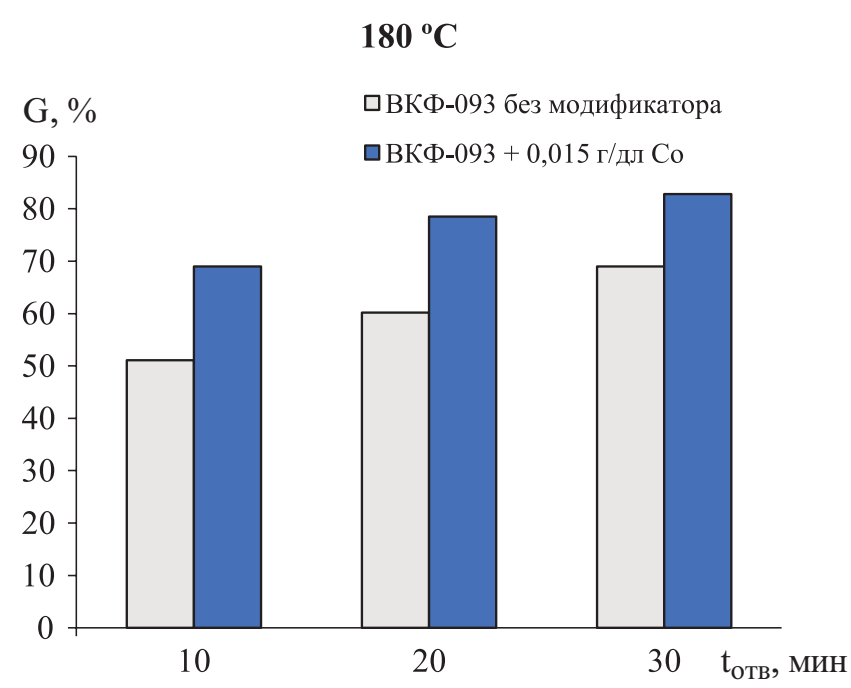

Рис. 7. Влияние времени отверждения покрытий на содержание G-фракции

тализатора отверждения позволило улучшить солестойкость покрытий с шести до двенадцати суток, а кислотостойкость с пяти до одиннадцати суток. Очевидно, это связано с увеличением степени структурирования пленок, о чем свидетельствуют результаты исследования G-фракции покрытий.

\section{Выводы}

Разработана методика введения катализатора - резината кобальта в состав водоразбавляемых композиций для электроосаждения на основе грунтовки ВКФ-093. Оптимизирован состав разработанной композиции, изучены её коллоидно-химические свойства и режимы нанесения 
на окрашиваемые поверхности. Показана высокая каталитическая активность резината кобальта на процессы структурирования электроосажденных покрытий, что дает возможность уменьшить продолжительность или температуру их формирования, тем самым значительно снизить энергоемкость производства.

Работа выполнена при финансовой поддержке Программы фундаментальных исследований РАН № $34 \Pi$.

\section{Лumepamypa}

1. Тагиров А.Р., Беспалова Г.Н., Ларин А.Н., Агеева T.A., Лебеденко А.О. Дизайн. Материалы. Технология. 2012. № 5 (25). С. 30-33.
2. Койфман О.И., Агеева Т.А. Порфиринполимеры: синтез, свойства, применение. - М.: ЛЕНАНД, 2018. $-300 \mathrm{c}$

3. Беспалова Г.Н., Ларин А.Н., Агеева Т.А., Морохина A.К., Моисеева К.Е., Койфман О.И. Химия и технология органических веществ. Тонкие химические технологии. 2016. Т. 11. №3. С. 79-85.

4. Карякина М.И. Лабораторный практикум по техническому анализу и контролю производств лакокрасочных материалов и покрытий. - М.: Химия. 1989. - 208 с.

5. Яковлев А.Д. Химия и технология лакокрасочных покрытий. - СПб.: ХИМИЗДАТ, 2008. С. 96-97.

6. Кочнев А.М., Заикин А.Е., Галибеев С.С., Архиреев В.П. Физикохимия полимеров. - Казань: Изд-во «Фэн». 2003. С. 410-427.

7. Беспалова Г.Н., Баранов А.П., Филиппова Е.В., Ларин А.Н. Промышленные покрытия. 2017. № 11-12. C. $60-65$. 